\title{
The Biochemistry of Heat Illness
}

\author{
Lt Col PJN Howorth \\ TD, MD, FRCPath, RAMC(V) \\ Consultant Pathologist
}

207 (Manchester) General Hospital RAMC(V), Manchester M16 7RS

SUMMARY: The two common forms of heat illness in the Services are heatstroke and heat exhaustion. Biochemical predisposing factors are considered for each. Susceptibility to malignant hyperthermia should $\mathscr{\Re e}$ tested for in cases of heat stroke. The heterozygote status for cystic fibrosis should be established in cases of hoुght exhaustion.

\section{Introduction}

Lt Col Dickinson's admirable review of heat illness in the Services did not consider biochemistry (1). In the past some fatalities could be attributed to faulty arrangements, as when four officer cadets at Aldershot died in the summer of 1948 during an endurance run wearing full denim gear with heavy packs (2). However in recent times, probably due to increased awareness, cases have tended to be sporadic. As Lt Col Dickinson noted himself (3), 'Some people seem to be unduly susceptible to hyperthermia on exercise even in moderate conditions and, sadly, the first episode may be the fatal one.' This paper reviews biochemical predisposing factors which might explain this observation.

Heat stroke and heat exhaustion are the two commonest forms of heat illness, having different aetiology, biochemistry, and predisposing factors.

\section{Heat stroke}

Heat stroke occurs in $13 \%$ cases of heat illness (1) and is caused by the body core overheating to over 41 deg.C. It is usually due to physical exertion in a climate with ambient temperature close to or above body temperature. Normally the sweat mechanism maintains a normal body temperature but heat stroke victims may cease to sweat. An RAMC medical officer working near Basra in 1943 where the noon shade temperature could reach 60 deg.C noted cessation of sweating in twelve survivors of heat stroke (4).

Clinically there is confusion, headache and a hot dry skin. Initially there is a respiratory alkalosis (low $\mathrm{PaCO} 2$ ) due to hyperventilation, followed by a metabolic acidosis (low blood $\mathrm{pH}$, high $\mathrm{H}$ ion conc.) and hyperlactataemia (5). The serum creatine kinase (CK) may be greatly elevated. Serum calcium may fall due to calcium binding to damaged cells. Later changes are organ failure (heart, kidney, liver), with disseminated intravascular coagulation and myoglobinuria due to rhabdomyolysis. These pathological changes were formerly thought to be due to intestinal endoxins absorbed into the portal circulation causing release of vasoactive mediators from target cells, such as macrophages (6).

Heat stroke and Malignant Hyperthermia
It was postulated in 1978 that malignant hypertheri is a human stress syndrome of which heat stroke is ofie variety (7). Two soldiers successfully treated for hב̄at stroke were later shown to be susceptible to malignånt hyperthermia by pharmacological tests on muscle biopy (8). Malignant hyperthermia is a pharmacogenedic disorder associated with disordered intracellular ionised calcium regulation. The skeletal muscle suffers sevege damage after a general anaesthetic using suxamethoniom or a volatile agent such as halothane or enflurane.-It occurs in about 1:50 000 adults, usually male, ådㅐ inherited as an autosomal dominant. The anaes drugs cause the calcium conc. to rise in muscle myopatm leading to muscle rigidity, hypermetabolisnand sarcolemmal disruption, with hyperkalaemiag myoglobinaemia. Although serum CK may be raised.'tn persons susceptible to malignant hyperthermia, CK toftg is thought to be unreliable for screening, and mali hyperthermia is diagnosed by in vitro contracture testsōn skeletal muscle samples (8). It is not known wat proportion of cases of heat stroke occur in pers®s susceptible to malignant hyperthermia.

\section{Heat stroke and Nitric Oxide}

The discovery that nitric oxide is the endotheliu而derived relaxing factor (9) has led to major advancessin understanding the role of nitric oxide as an importit intercellular messenger. Nitric oxide has both benefictal and deleterious roles (10) and is 'bad' in heat stroße. Clark et al (11) observed that the changes in mental stais during cerebral malaria, heat stroke, and recovery from major surgery are clinically similar. A War Off Ee publication from 1942 (12) noted that the neurologioal symptoms of heat stroke are easily mistaken for thosejof cerebral malaria. Equally ethanol-induced coma abf opioid narcosis can be clinically very similar to cerebial malaria suggesting that a common biochemiọal mechanism is involved in causing what are usuanty reversible neurological changes.

In heat stroke there are high circulating levels of 셩 cytokines tumour necrosis factor (TNF) and interleukifot 1 (IL-1) which strongly induce nitric oxide formationoin vivo (13). These cytokines can induce nitric oxde 
formation in vascular walls which can then diffuse across the blood-brain barrier causing functional changes including inhibition of calcium entry, reduced activity of the calcium-dependent nitric oxide synthase, and thus reduced nitric oxide formation in post-synaptic neurones.

Thus the current hypothesis for the biochemical mechanisms for the neurological changes in heat stroke is that cytokine-induced nitric oxide release interferes with the normal excitatory function of neuronal nitric oxide. The biochemical pathway involves intracellular ionised calcium which links heat stroke with malignant hyperthermia. It is suggested that Service personnel recovering from heat stroke should be investigated for susceptibility to malignant hyperthermia.

\section{Heat Exhaustion}

Heat exhaustion accounts for $74 \%$ cases of heat illness in service personnel (1). It is usually caused by loss of extra-cellular fluid (ECF) through a salty-sweat whilst working in a hot environment. Patients may collapse, or be greatly fatigued, with nausea, vomiting, and painful muscle cramps. Since salt and water are lost the serum sodium and chloride concentrations are normal, but the haematocrit and serum urea and osmolality are raised. The clinical picture is thus similar to loss of ECF from the gut, as in a dysentery. If ECF volume becomes critically low peripheral circulatory failure and prerenal uraemia can ensue.

A less common variant is when water loss exceeds salt loss, as when persons are deprived of water in a hot environment. Water deprivation may be voluntary as in pilgrims to the Hadj in Mecca and as described below. Water is then lost from the whole body, cell fluid and ECF. Death occurs when $15-25 \%$ body weight is lost.

\section{Heat Exhaustion and Cystic Fibrosis}

Children with cystic fibrosis have a high salt content to their sweat and have a reduced tolerance to climatic heat stress. It has been suggested that this high sweat salt content reduces the normal thirst stimulus which is a rise in body fluid osmolality (14). Children with cystic fibrosis when not forced to drink in hot environmental conditions can greatly underestimate their fluid needs (voluntary dehydration).

The relevance of this to heat exhaustion is that 1:20 to $1: 25$ of the general population is heterozygous for cystic fibrosis. It is not yet known whether heterozygotes for cystic fibrosis have a marginally saltier sweat than nonheterozygotes, but it is a logical hypothesis. This has been a theoretical possibility for many years, but the situation has now changed because cystic fibrosis heterozygote status can now be determined by DNA analysis of mouthwash samples collected in $4 \%$ sucrose (15). I suggest that service personnel recovering from heat exhaustion should have their cystic fibrosis heterozygote status ascertained.

\section{REFERENCES}

1. Dickinson JG. Heat illness in the Services. $J R$ Army Med Corps 1994; 140: 7-12.

2. LINSELL WD. Heat illness in servicemen. Lancet 1989; 2: 803.

3. Dickinson JG. Heat stroke and the Armed Forces. Lancet 1989; 2: 1102.

4. Waterlow JC. Heat stroke and the Armed Forces Lancet 1989; 2: 1280-1.

5. Stoneham MD, Price DJA. Acid-base disturbances and heat-stress in the armed forces. Lancet 1992 339: 870-1.

6. ANONYMOUS. Endotoxins in heatstroke. Lancet 1989; 2: 1137-8.

7. Wingard DW, Gatz EE. Some observations on stress susceptible patients. In: Aldrete JA, Britt FA, eds. The second international symposium on malignant hyperthermia. New York: Grune and Stratton 1978; 363-72.

8. Hopkins PM, Ellis FR, Halsall PJ. Evidence fo甲 related myopathies in exertional heat stroke an\& malignant hyperthermia. Lancet 1991; 338: 1491-2

9. Palmer RMJ, Ferrige AJ, Moncada S. Nitrig oxide release accounts for the biological activity endothelium-derived relaxing factor. Nature 1987 327: 524-6.

10. Schmidt HHHW, Warner, TD, Murad F. Double-edged role of endogenous nitric oxide. Lancet 1992; 339: 986.

11. Clark IA, Rockett Ka, Cowden WB. Possible central role of nitric oxide in conditions similar to cerebral malaria. Lancet 1992; 340: 894-6.

12. Anonymous. Memorandum 24 on medical diseases in tropical and sub-tropical areas. London, The War Office: 154-5 (McLaren, Melbourne, 1942).

13. RocketT KA, Awburn MA, AgGarwal BB, et al. In vivo induction of nitrite/nitrate by TNF, LT and 11-1: roles in malaria. Infect Immun 1992; 60: 3725 30.

14. BAR-Or O, BLIMKIE CJR, HAY JA, et al. Voluntary dehydration and heat intolerance in cystic fibrosis. Lancet 1992; 339: 696-9.

15. Super M, Schwarz MJ, Malone G, et al. Active 을 cascade testing for carriers of cystic fibrosis gene $\mathrm{Br}$ D Med J 1994; 308: 1462-7. 